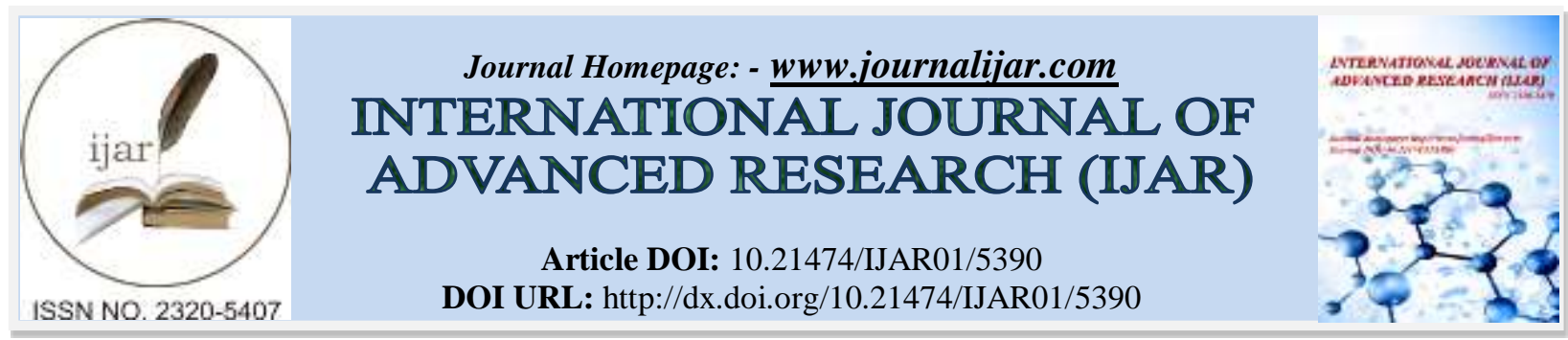

RESEARCH ARTICLE

\title{
COMPARATIVE EVALUATION OF MICROLEAKAGE OF FOUR DIFFERENT DIRECT RESTORATIVE MATERIALS (AMALGAM, BONDED AMALGAM, PACKABLE COMPOSITE AND PACKABLE COMPOSITE WITH FLOWABLE COMPOSITE LINER) IN CLASS II RESTORATIONS USING STEREOMICROSCOPE - AN IN-VITRO STUDY.
}

Neelanjana Majumdar ${ }^{1}$, Paromita Mazumdar ${ }^{2}$ and Utpal Kumar Das ${ }^{3}$.

1. Post Graduate student, Department of Conservative Dentistry \& Endodontics, Guru Nanak Institute of Dental Sciences and Research, 157/F Nilgunj Road, Panihati, Kolkata-700114.

2. Professor and H.O.D, Department of Conservative Dentistry \& Endodontics, Guru Nanak Institute of Dental Sciences and Research, 157/F Nilgunj Road, Panihati, Kolkata-700114.

3. Professor, Department of Conservative Dentistry \& Endodontics, Guru Nanak Institute of Dental Sciences and Research, 157/F Nilgunj Road, Panihati, Kolkata-700114.

\section{Manuscript Info}

Manuscript History

Received: 10 July 2017

Final Accepted: 12 August 2017

Published: September 2017

Key words:-

Marginal Microleakage, Amalgam; Bonded Amalgam; Packable Composite (Nano-Hybrid Composite); Flowable Composite as a Lining Material with Packable Composite (Nano-Hybrid Composite).

\section{Abstract}

Aim: The aim of the study is to compare the microleakage of four different direct restorative materials (amalgam, bonded amalgam, packable composite and packable composite with flowable composite liner) in class II restorations using stereomicroscope.

Materials and Methods: A standardized Class II cavity preparation was made involving the proximal and occlusal surfaces. All prepared samples were randomly divided into 4 experimental groups, with 10 teeth each according to the restoration material used: Group IAmalgam; Group II- Bonded amalgam; Group III- Packable composite (Nano-hybrid composite); Group IV- Flowable composite as a lining material with Packable composite (Nano-hybrid composite). The restored teeth were stored for 24 hours in distilled water, and thermocycled for 500 cycles between $5^{\circ} \mathrm{C}$ and $55^{\circ} \mathrm{C}$ with a dwell time of 30 seconds in each bath. Samples were immersed in $0.5 \%$ basic fuschine dye for 24 hours. The teeth were sectioned along the mesiodistal direction. The dye penetration of the occlusal and gingival margins of each section was evaluated independently by the observer using a stereo-microscope (Olympus, F. No. 19-34/ 2008-RE).

\section{Conclusion:}

1. According to the Statistical Analysis, lower microleakage scores were observed in amalgam and bonded amalgam. Higher microleakage scores were observed in nano hybrid and nano hybrid with flowable material.

2. Mean microleakage score of Group-3 (Nano hybrid) was the highest of all groups. Mean microleakage score of Group-2 (Bonded amalgam) was the lowest of all groups.

3. As per the critical differences (CD) the mean microleakage score of Group-2(Bonded amalgam) was significantly lower than that of Group-1(Amalgam), Group-3(Nano hybrid) and Group-4(Nano hybrid + Flowable $)(\mathrm{p}<0.01)$.

Corresponding Author:- Neelanjana Majumdar.

Address:- Post Graduate student, Department of Conservative Dentistry \& Endodontics, Guru 
4. Also the mean microleakage score of Group-2 (Bonded amalgam) was significantly lower than all groups but no statistically significant difference was found in mean microleakage score of Group-2 (Bonded amalgam) and Group-1 (Amalgam).

Copy Right, IJAR, 2017,. All rights reserved.

\section{Introduction:-}

The integrity and durability of the marginal seal is essential for any restorative system to maintain pulpal health and to increase the longevity of the restoration. A proximo-occlusal conventional preparation illustrates and designates walls, line angles and point angles. Dentistry had always thrived to achieve biocompatible restorations that do not compromise the pulp and also maintain the dental seal. Some of the problems confronting clinicians when placing resin composites in Class II cavities include difficulty in obtaining proximal contact, adhesion to placement instruments and poor adaptation (Belvedere, 1999; Leinfelder, Radz \& Nash, 1998). These cavities are extended different bonding substrates, enamel at the occlusal and dentin at the gingival margins. Bonding of resins to dentin is more difficult and less predictable than bonding to enamel because dentin includes fewer mineral but more organic and water content than enamel. A cohesive bond to dentin is achieved by diffusion of hydrophilic resins into and around the collagen fibers of etched intertubular dentin [1].

Dental amalgam remains the predominant direct material for load-bearing restorations in posterior teeth. It has many advantages as a restorative material, because it is strong, durable and easy to use. Some of its disadvantages, however, include its metallic grey color and lack of adhesive properties, making undercuts for mechanical retention necessary. Microleakage has been identified as a significant problem with amalgam due to interfacial gap formation, which may cause tooth discoloration, pulp irritation and secondary caries. Although corrosion products from amalgam alloy may eventually seal the interfacial gap between the tooth surface and the amalgam restoration. The microleakage of amalgam restorations may be reduced through adequate cavity preparation, conventional varnish application, and use of dentin adhesives, proper amalgam condensation and amalgam burnishing [2].

However, the shift to posterior resin composite materials became popular in the mid-1990s. The change from amalgam to composite restorations was most prevalent for one-surface restorations. In recent years, resin-based composite restorations have become an increasingly popular alternative to amalgam direct restorations in the posterior dentition, owing to their excellent esthetic and other favourable characteristics. The major disadvantage of visible light-cured composites is polymerization shrinkage. This shrinkage can result in a gap formation between the composite material and tooth structure, particularly if the restoration margin is placed in dentin or cementum. Bacteria, fluids, molecules, or ions can pass through this gap between the resin composite and the cavity wall, a process called microleakage. [3] Microleakage is thought to be responsible for hypersensitivity, secondary caries, pulpal pathosis and failure of restorations. Besides pulpal irritation and secondary caries, microleakage also results in marginal discoloration [4].

Complete penetration into the entire depth of the demineralized zone is necessary to prevent bacterial microleakage and recurrent caries. The initial effectiveness and durability of the interface between the resin composite and tooth tissues may be described as a simple relationship between the bond strength and the stress generated by polymerization shrinkage. With time, stresses caused by other factors such as occlusal loading and thermal changes will add to the process. To ensure a successful restorative procedure the bonded interface area must be capable of withstanding those stresses.

The elastic modulus of the restorative composite has been reported to be an important factor for the generation of shrinkage stresses: as the elastic modulus increases, more shrinkage stress transmitted to the interface with less relief.3 The hybrid layer has a relatively low elastic modulus to relieve polymerization shrinkage stresses that work as a stress absorbing layer [5].

Several manufacturers have introduced "condensable" or "packable" composites as alternatives to amalgam (Leinfelder, 1997; Leinfelder \& others 1998). Packable composites use amalgam techniques for placement and produce acceptable interproximal contacts (Leinfelder \& others, 1998). Because of the high depth of cure and low 
polymerization shrinkage of packable composites, a bulk-fill technique may be possible (Affleck \& others, 1999; Aw \& Nicholls, 1999). However, concerns related to the ability of these stiffer materials to adequately adapt to internal areas and cavosurface margins have been raised, particularly at the cervical.

To offset this problem, using "flowable" composites as liners has been suggested. Flowable composites have low viscosity and may adapt to the cavity better than packable composites (Bayne \& others, 1998) [6].

This in vitro study compared marginal microleakage in Class II cavities restored with amalgam, bonded amalgam, packable composites and packable composites with a flowable liner. Microleakage of occlusal and gingival margins of Class II cavities was evaluated using stereo-microscope.

\section{Materials and methods:-}

In total, 20 sound mandibular first molars, with neither carious lesions nor restorations, which were recently extracted, selected for this in vitro study. Each tooth underwent scaling and root planing with an ultrasonic device to remove residual organic tissue. Then, the teeth were immersed in $2.6 \%$ sodium hypochlorite solution and rinsed with running water for $10 \mathrm{~min}$.

\section{Cavity preparation:-}

A standardized Class II cavity preparation was made involving the proximal and occlusal surfaces using No.245 tungsten carbide bur in a high-speed airotor hand piece with water spray. The overall dimensions and depths of cavities were standardized (occlusal floor, width $4 \mathrm{~mm}$, length $5 \mathrm{~mm}$; axial wall, width $4 \mathrm{~mm}$, height $3 \mathrm{~mm}$; gingival floor, width $4 \mathrm{~mm}$, depth $2.5 \mathrm{~mm}$. The proximal boxes ended in dentin and the gingival cavosurface margin $1 \mathrm{~mm}$ above the CEJ with the cavosurface margins as butt joint.

\section{Restorative procedures:-}

All prepared samples were randomly divided into 4 experimental groups, with 10 teeth each according to the restoration material used: Group I- Amalgam; Group II- Bonded amalgam; Group III- Packable composite (Nanohybrid composite); Group IV- Flowable composite as a lining material with Packable composite (Nano-hybrid composite).

\section{Study design:-}

The 40 samples so prepared will be divided into groups as follows and subjected to experimentation.

Group I: The silver amalgam was placed in the cavity using the amalgam carrier and condensed properly with the help of amalgam condenser without any liner application.

Group II: The cavities were etched with 37\% phosphoric acid for 30 seconds (Eco-Etch, Etching Gel, Ivoclar Vivadent), rinsed with air/water spray. Blot excess water using a cotton pellet or mini-sponge. Immediately after blotting, apply 2-3 consecutive coats of adhesive (Adper Single Bond 2, 3M ESPE) for 15 seconds with gentle agitation using a fully applicator and light-cured for 10 seconds. The silver amalgam was placed in the cavity using the amalgam carrier and condensed properly with the help of amalgam condenser.

Group III: The cavities were etched with 37\% phosphoric acid for 30 seconds (Eco-Etch, Etching Gel, Ivoclar Vivadent), rinsed with air/water spray for 20 seconds followed by gentle drying for 5 seconds and bonded with total etch dental adhesive (Tetric N-Bond, ivoclar vivadent). The cavities were restored with packable composite (Filtek Z250 XT, 3M, Nano Hybrid Universal Restorative composite), using the oblique incremental technique with each increment being $2 \mathrm{~mm}$. Each increment was cured for 20 seconds from the occlusal aspect. The restoration was then light cured from the buccal and lingual aspects for 20 seconds each after the matrix band was removed.

Group IV: The cavities were etched with 37\% phosphoric acid for 30 seconds (Eco-Etch, Etching Gel, Ivoclar Vivadent), rinsed with air/water spray for 20 seconds followed by gentle drying for 5 seconds and bonded with total etch dental adhesive (Tetric N-Bond, ivoclar vivadent). Flowable composite resin (Any-Com Flow, Nano hybrid flowable zirconium composite resin) was injected onto the gingival floor of the cavity to a thickness of approximately $1 \mathrm{~mm}$ and light cured for 20 seconds. The thickness was controlled referring to the original cavity depth using a standard William's periodontal probe. The cavity was then restored with packable composite (Filtek Z250 XT, 3M, Nano Hybrid Universal Restorative composite), using the oblique incremental technique with each increment being $2 \mathrm{~mm}$. Each increment was cured for 20 seconds from the occlusal aspect. The restoration was then light cured from the buccal and lingual aspects for 20 seconds each after the matrix band was removed. 


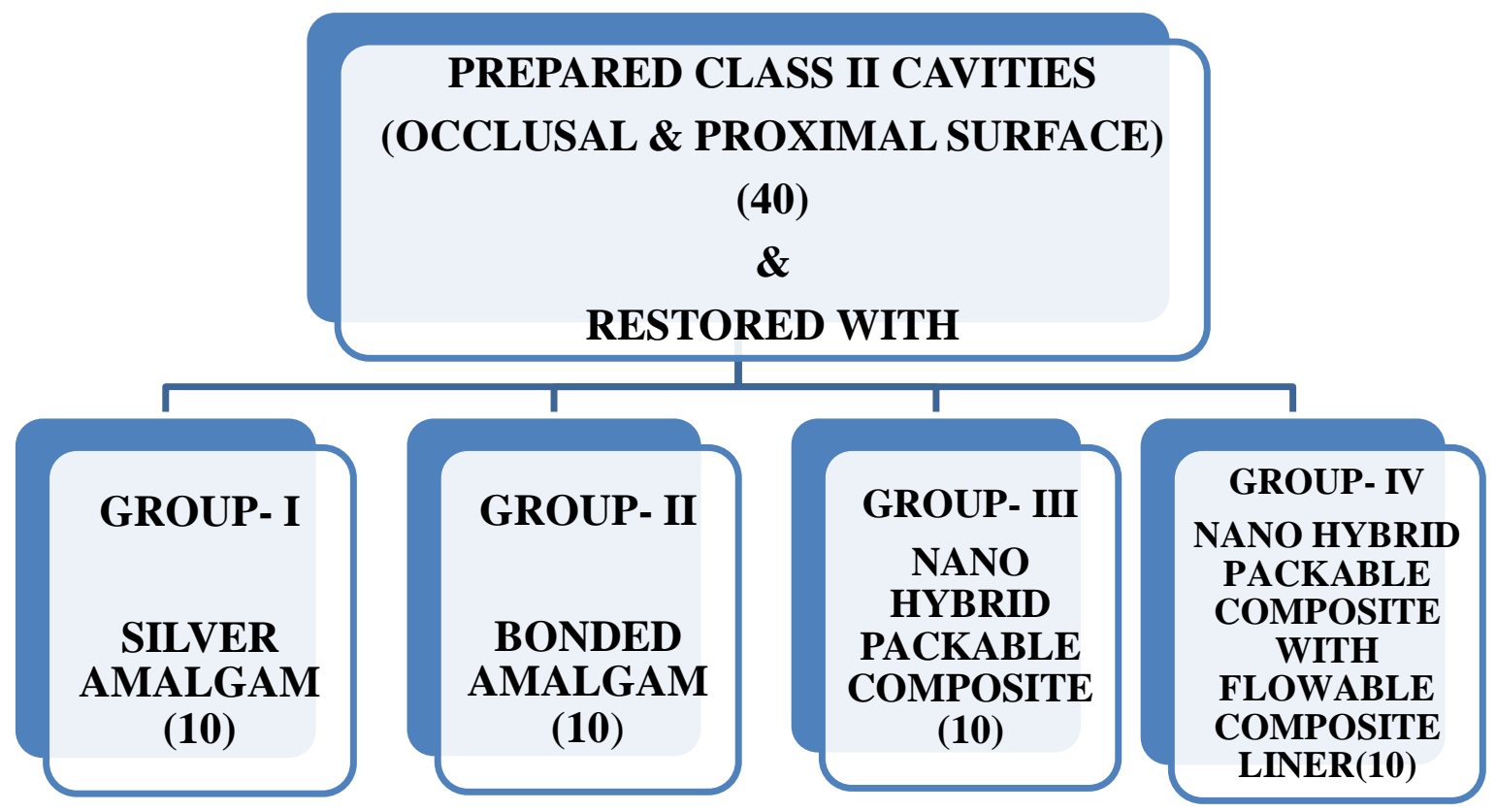

Method:-

- $\quad$ The restored teeth were stored for 24 hours in distilled water, and thermocycled for 500 cycles between $5^{\circ} \mathrm{C}$ and $55^{\circ} \mathrm{C}$ with a dwell time of 30 seconds in each bath.

- The apices of the specimens were sealed with sticky wax.

- All tooth surfaces were covered with two coats of clear nail polish with exception of $1.0 \mathrm{~mm}$ around the toothrestoration margins and allowed to air dry.

- Samples were immersed in $0.5 \%$ basic fuschine dye for 24 hours.

- The teeth were sectioned along the mesio-distal direction, coincident with the center of the restoration, with a sectioning diamond disc under water spray from chip syringe.

- The dye penetration of the occlusal and gingival margins of each section was evaluated independently by the observer using a stereo-microscope. (Olympus, F. No. 19- 34/ 2008-RE) at a magnification $2.5 \times 10 \mathrm{X}$ and the microleakage of occlusal and gingival margins of Class II cavities were recorded based on the following criteria.

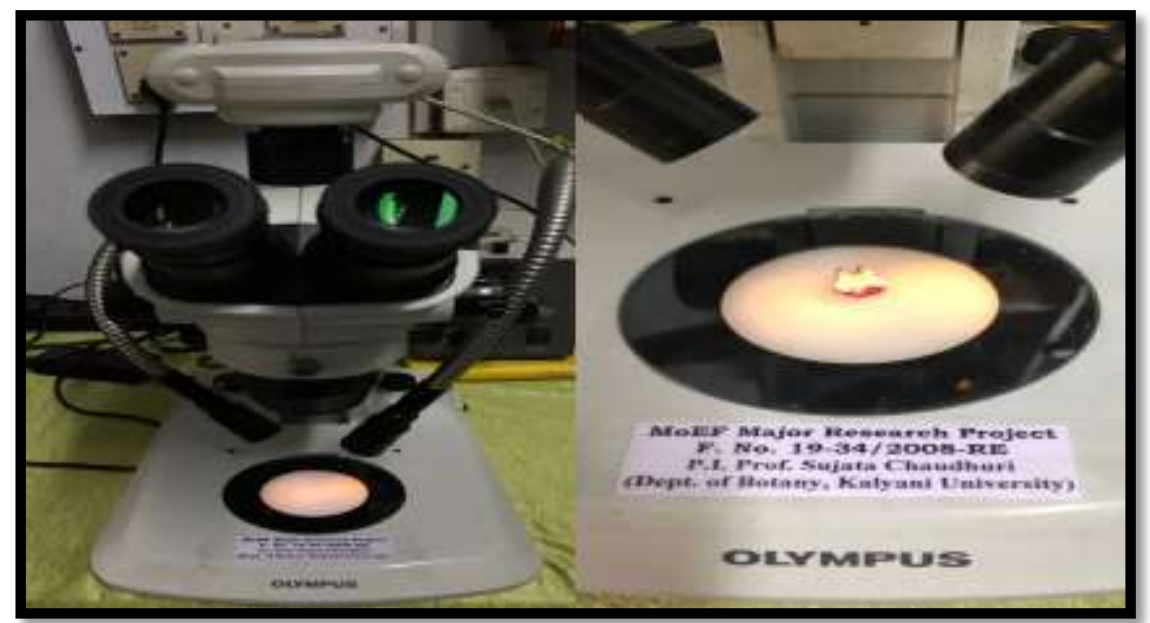

(OLYMPUS, F. NO. 19- 34/ 2008-RE), MAGNIFICATION $2.5 \times 10 \mathrm{X}$

Dr. Utpal Basu, Head of the Department (HOD), Department of Molecular Biology \& Biochemistry,University of Kalyani 


\begin{tabular}{|l|l|c|}
\hline SCORE & $\begin{array}{l}\text { TOOTH-RESTORATION } \\
\text { INTERFACE }\end{array}$ & $\begin{array}{l}\text { SCORE } \\
\text { PROPORTIONS) }\end{array}$ \\
\hline 1 & Co dye penetration & 0.00 \\
\hline 2 & $\begin{array}{l}\text { dye penetration up to the first third } \\
\text { of the prepared cavity wall }\end{array}$ & 0.25 \\
\hline 3 & $\begin{array}{l}\text { dye penetration up to the second } \\
\text { third of the prepared cavity wall }\end{array}$ & 0.50 \\
\hline 4 & $\begin{array}{l}\text { dye penetration onto the entire } \\
\text { prepared cavity wall }\end{array}$ & 0.75 \\
\hline 5 & $\begin{array}{l}\text { dye penetration onto the entire } \\
\text { prepared cavity wall and the pulpal } \\
\text { wall }\end{array}$ & 1.0 \\
\hline
\end{tabular}

The leakage number was taken from the following ratio:

Distance evidenced for dye

Leakage Number $=$

Overall distance determined for margin $(=100 \%)$

The leakage distance from the margins to the determined limit was recorded in $\mathrm{mm}$, and the leakage number was a result of the proportion of dye leakage.

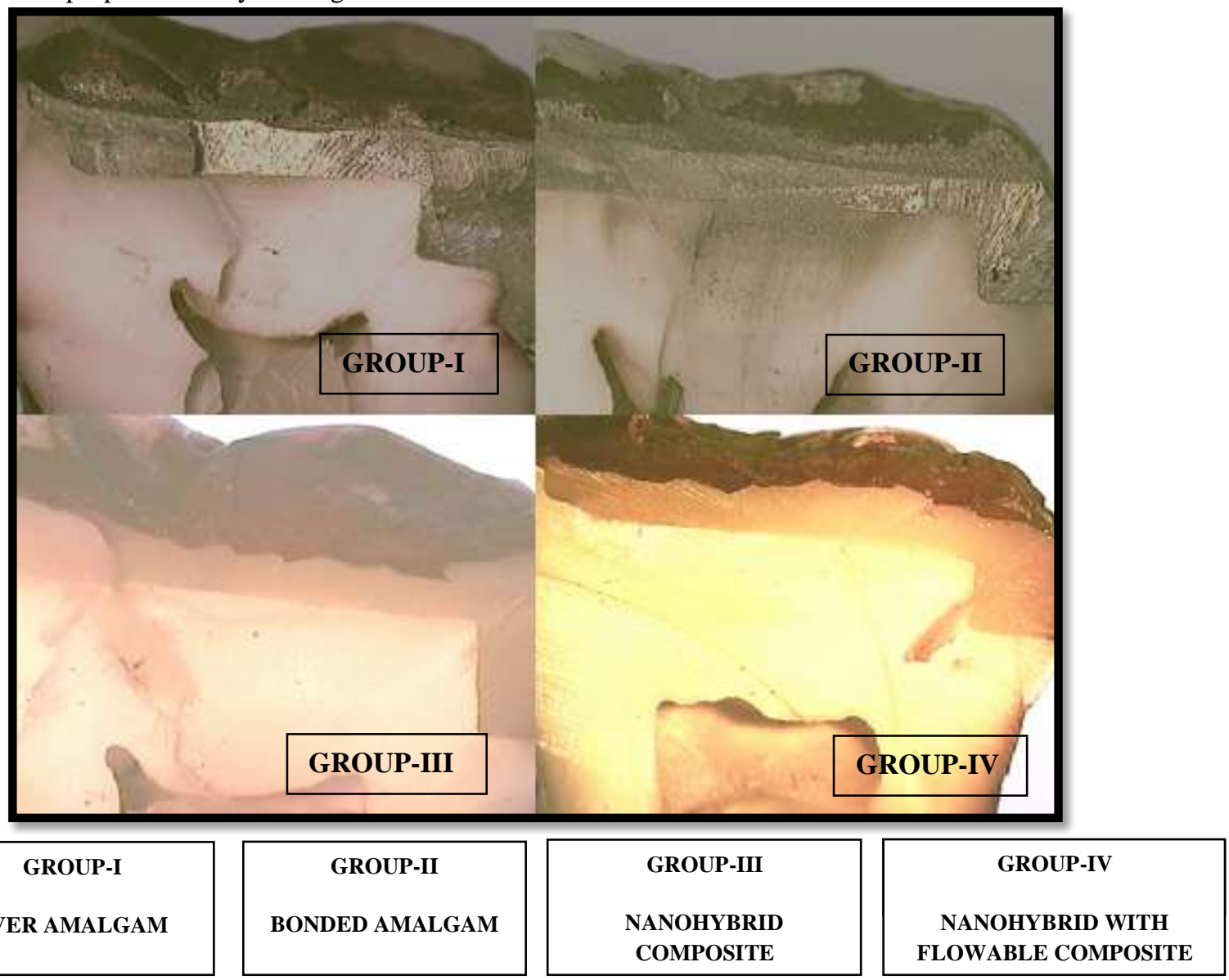

Stereomicroscopic View Of Longitudinally Sectioned Teeth Showing Extent Of Microleakage ( Dr. Utpal Basu, Head of the Department (HOD), Department of Molecular Biology \& Biochemistry,University of Kalyani ) 


\section{Data Analysis:-}

Descriptive statistical analysis was performed to calculate the means with corresponding standard deviation (s.d.). Also One Way Analysis of variance (ANOVA) followed by post hoc Tukey's Test was performed with the help of Critical Difference (CD) or Least Significant Difference (LSD) at 5\% and 1\% level of significance to compare the mean values. $\mathrm{p}<0.05$ was taken to be statistically significant.

\section{Results:-}

Table-1: Distribution of microleakage score of different materials

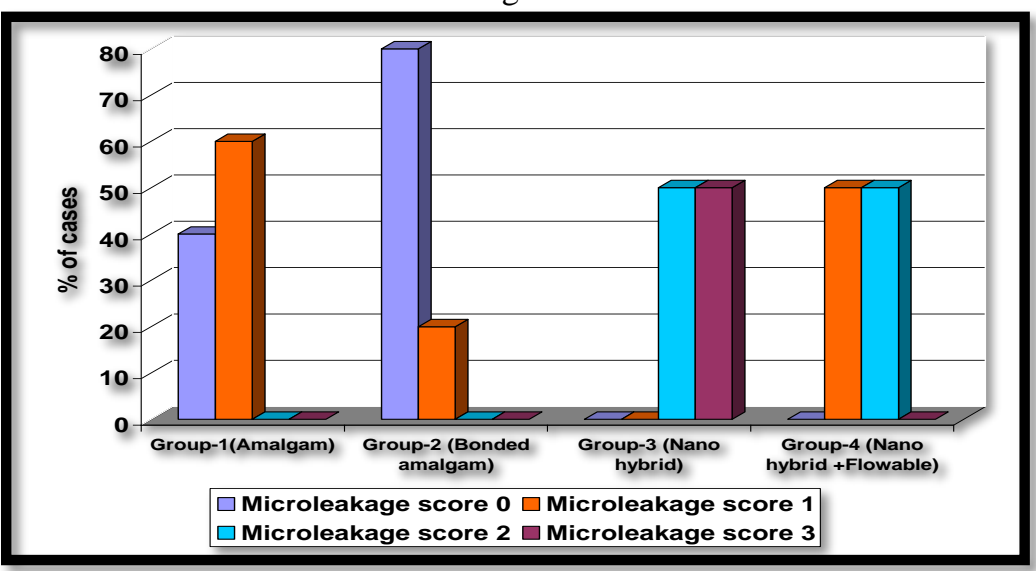

- According to the Statistical Analysis, lower microleakage scores were observed in amalgam and bonded amalgam. Higher microleakage scores were observed in nano hybrid and nano hybrid with flowable material.

Table-2: Mean (mean \pm s.d.) microleakage score of different materials

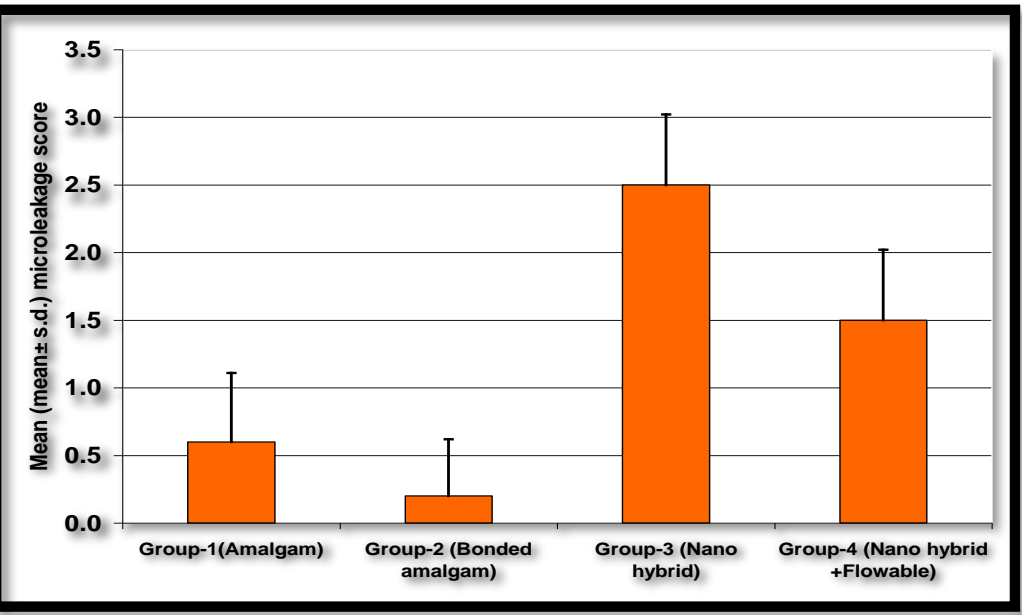

- Mean microleakage score of Group-3 (Nano hybrid) was the highest of all groups. Mean microleakage score of Group-2 (Bonded amalgam) was the lowest of all groups.

- As per the critical differences (CD) the mean microleakage score of Group-2(Bonded amalgam) was significantly lower than that of Group-1(Amalgam), Group-3(Nano hybrid) and Group-4(Nano hybrid +Flowable $)(\mathrm{p}<0.01)$.

- Also the mean microleakage score of Group-2 (Bonded amalgam) was significantly lower than all groups but no statistically significant difference was found in mean microleakage score of Group-2 (Bonded amalgam) and Group-1 (Amalgam).

\section{Discussion:-}

- Microleakage is still a concern in restorative dentistry, as it has been related to pulp alterations, sensitivity and secondary caries, marginal discoloration which are the most common causes of restoration failure (Manhart \& others, 2004). Currently, no outstanding method is available to determine microleakage (Alani \& Toh, 1997). 
Despite the limitations, dye leakage methodology remains a popular tool to investigate the sealing ability of restorative materials, due to its low cost and the technique being very simple (Raskin \& others, 2001). Furthermore, measurements of marginal-sealing effectiveness and bond-strength testing (the two most commonly employed methodologies to determine bonding capacity in the laboratory) are valuable for predicting clinical performance (Van Meerbeek \& others, 2003) [1].

- Dye leakage was higher in the cementum/dentin margins, which is in agreement with previous reports (Marchiori \& others, 1998; Meiers \& Turner, 1998; Cenci \& others, 2004). This difference is related to the difference in mineral composition between the two substrates. While enamel is a highly mineralized tissue, dentin is less mineralized, thus, presenting more organic compounds. Also, dentin is a moist tissue, making bonding with adhesive more unstable (Van Meerbeek \& others, 2003). In addition, cementum /dentin is more porous, enhancing the permeability to dye penetration in relation to enamel [1].

- Immediately after packing the amalgam, a rapid contraction may be observed, followed by a slower expansion, then a slight and slow contraction. The net contraction and expansion of an amalgam restoration during setting is defined as 'dimensional change.' Dimensional change is considered negative, if the amalgam contracts, and it is considered positive, if it expands during setting, but ANSI/ADA requires that the dimensional change between five minutes and 24 hours must fall within the range of -15 to $+20 \mu \mathrm{m} / \mathrm{cm}$. High copper alloys show the lowest change.27 In the current study, the lathe-cut high copper single composition Cavex Avalloy (Silver Tin Dental Amalgam Alloy, DPI Alloy, silver content 68.7\%) was used. The "dimensional change" was indicated by the manufacturer as +1 . Amalgam does not adhere to tooth structure; therefore, a positive dimensional change would result in less gap formation between amalgam and the tooth structure [6].

- Numerous in vitro studies demonstrated that bonded amalgam restorations effectively reduced marginal leakage. For example, Belli, Amin et al [2006] [7] reported that microleakage values were significantly reduced in lined amalgam restorations when compared to unlined amalgam. Muniz et al [2005] [8] observed that a filled adhesive system applied by two methods (light and chemical curing) showed the best performance in the sealing and retention of amalgam restorations.

- $\quad$ There is evidence of decreased leakage of fluids with amalgam bonding systems, compared to non-coated or varnish-coated amalgam walls. Al-Jazairy and Louka demonstrated a significant reduction in microleakage around amalgam restorations when Amalgam bond Plus or All-V Bond 2 was used as a liner compared to either Copalite varnish or no liner. Under most other conditions, however, bonded amalgam restorations performed in a similar way to conventional amalgam restorations with cavity varnish or liner [9].

- Composite resins on their own do not possess the capability of bonding to either enamel or dentin. The inability to bond coupled with marked polymerization shrinkage and thermal expansion or contraction predispose to marginal leakage. Hence microleakage at the enamel restoration interface can be eliminated almost completely if sufficient enamel thickness is present but does not protect the dentin restoration interface completely. The tight adhesion to dentin is limited by a number of factors like vitality of the dentin, difference in physical and chemical composition of dentin compared to enamel, presence of dentinal fluid, smear layer etc. Development of internal stresses from polymerization shrinkage and thermal effects detrimental effect on the bond. Microleakage therefore continues to be a problem in almost all composite restoration [10].

- $1 \mathrm{~mm}$ of FRC liner improved the sealing ability than a $2 \mathrm{~mm}$ thick intermediate layer. These results are in agreement with the studies which showed a reduction in the microleakage when a thin lining was used. But it would be very demanding to confirm to a thickness of $1 \mathrm{~mm}$ in a deep proximal box. Verification of intermediate layer thickness in a deep proximal box is more difficult in a clinical situation. The wear rate of FRC is higher than that of the packable composites. Therefore, it has been proposed that FRC should be used in only contact free areas. The FRC have a less filler loading and shrink more when used in greater thickness. The results are also in agreement with a study which showed that restorations with thick FRC lining exhibited reduced perfect margin and the potential risk of marginal degradation. The application of $1 \mathrm{~mm}$ FRC is considered clinically acceptable [11].

\section{Conclusions:-}

Within the limitations of the current study, the following conclusions were drawn:

5. According to the Statistical Analysis, lower microleakage scores were observed in amalgam and bonded amalgam. Higher microleakage scores were observed in nano hybrid and nano hybrid with flowable material.

6. Mean microleakage score of Group-3 (Nano hybrid) was the highest of all groups. Mean microleakage score of Group-2 (Bonded amalgam) was the lowest of all groups. 
7. As per the critical differences (CD) the mean microleakage score of Group-2(Bonded amalgam) was significantly lower than that of Group-1(Amalgam), Group-3(Nano hybrid) and Group-4(Nano hybrid + Flowable $)(\mathrm{p}<0.01)$.

8. Also the mean microleakage score of Group-2 (Bonded amalgam) was significantly lower than all groups but no statistically significant difference was found in mean microleakage score of Group-2 (Bonded amalgam) and Group-1 (Amalgam).

\section{References:-}

1. T Alptekin et al (2010), In Vivo and In Vitro Evaluations of Microleakage Around Class I Amalgam and Composite Restorations, Operative Dentistry, 2010, 35-6, 641-648

2. Ottenga ME et al (2007), Amalgam and composite posterior restorations: Curriculum versus practice in operative dentistry at a US dental school Operative Dentistry 32(5) 524-528.

3. Morrow LA et al (2002), Microleakage of amalgam cavity treatment systems: An in vitro evaluation American Journal of Dentistry 15(4) 262- 267.

4. Belli S et al (2001) Effect of cavity varnish, amalgam liner or dentin bonding agents on the marginal leakage of amalgam restorations Journal of Oral Rehabilitation 28(5) 492-496.

5. Gaengler P et al (2001) Clinical evaluation of posterior composite restorations: The 10-year report The Journal of Adhesive Dentistry 3(2) 185-194.

6. Powers JM et al (2008) Dental Materials Properties and Manipulations Mosby Elsevier, St Louis.

7. Amin WM (2006) Comparative study of the sealing efficacy of various bonding systems to Class V dental amalgam restorations International Journal of Adhesion \& Adhesives 26(3) 145-150.

8. Muniz $\mathrm{M}$ et al (2005) Bonded amalgam restorations: Microleakage and tensile bond strength evaluation Operative Dentistry 30(2) 228- 233.

9. Da Silva AF et al (2006) Microleakage in conventional and bonded amalgam restorations: Influence of cavity volume Operative Dentistry 31(3) 377-383.

10. Textbook of Operative Dentistry, Vimal K Sikri, Fourth Edition

11. Kishore Kumar Majety et al (2011) In vitro evaluation of microleakage of class II packable composite resin restorations using flowable composite and resin modified glass ionomers as intermediate layers 2011 Oct Dec; 14(4): 414-417. 